\title{
Palimpsest and heterotopia, metaphors of the Circular Economy ${ }^{\text {is }}$
}

\author{
Jean-Pierre Birat ${ }^{*}$ \\ IF Steelman, Semécourt, France
}

\author{
Received: 20 August 2019 / Accepted: 21 November 2019 \\ "We must think that what exists is far from filling all possible spaces" Michel Foucault, 1980
}

\begin{abstract}
Words like palimpsest or heterotopia do not belong to the working vocabulary of materials or engineering sciences: they are used in Social Sciences and Humanities (SSH). A palimpsest is a manuscript written on an older document, the text of which has been erased. Heterotopia is a young word forged by Michel Foucault in 1967 to describe a closed space, the boundaries of which mark a discontinuity in terms of behavior: a jail or a monastery are thus a heterotopia. The Circular Economy $(C E)$ is an essential concept in the framework of the ecological transition, pulled by a series of converging economic, ecological and political drivers. It is usually described as the adoption of a circular model of production to replace the "linear model', but also as the new buzzword to describe material efficiency, the 3-R rule, the zero-waste ideal, the concepts of lean or frugal design or their reformulation by the Ellen Macarthur Foundation, as a societal challenge and an ethical necessity. Materials producers claim that they have been practicing the Circular Economy since long before the expression was ever invented, thus à la Monsieur Jourdain, etc. The point of this paper is to describe the Circular Economy as a palimpsest and as a heterotopia and to use the metaphors, if indeed they are only metaphors, to highlight some of the less obvious features of the CE. A palimpsest is a parchment or a papyrus, which is used several times to support a series of consecutive texts. Secondary raw materials are like a palimpsest, because there are retrieved from a previous life and used again in a second life: a new artefact made from that material is like a new text written on/with this material-a metaphor also used, mutatis mutandis, in expressions like 3-D printing or laser scribing. Some interesting features of the CE pointed out by the metaphor: a the palimpsest can be used several times, like a material can be recycled several times; the concept of the palimpsest posits that the parchment is somehow more important than the text that is written on it, therefore a material is more important than the goods that are made of it; the palimpsest was used before the invention of paper and, similarly, the Circular Economy was the standard model before mass production of cheap consumer goods imposed the so-called "linear model"; a palimpsest keeps a fragmented memory of the past, in the same way as recycled material maintains a link to its past lives, through its composition in tramp elements. Examples of heterotopia are a prison or a cemetery. The Circular Economy defines a space where a particular material/element exists in its various avatars, impersonations and reincarnations and this may tentatively be worked out as a heterotopia. This is a more complex endeavor than discussing the palimpsest metaphor, but a potentially more fruitful one. Foucault has provided criteria defining heterotopia which can help us explore the analogy: particularly the point that such a space is either a space of illusion or a space of perfection. This analysis is original because it hybridizes materials and SSH concepts and thus fits with the exploration of the frontier between materials and society that SAM conferences are concerned about.
\end{abstract}

Keywords: Circular Economy / material efficiency / geobiochemical cycle / palimpsest / heterotopia / metaphor / materials / SSH

Résumé. Le palimpseste et l'hétérotopie, des métaphores de l'économie circulaire. Des mots comme palimpseste et hétérotopie n'appartiennent pas au vocabulaire courant des sciences des matériaux ou de l'ingénieur: ils sont plutôt utilisés en sciences humaines et humanités (SHH). On appelle palimpseste, un manuscrit recopié sur un document plus ancien, dont le texte a été effacé. Hétérotopie est un mot récent inventé

\footnotetext{
is Presented to the 13th Conference on Society and Materials, SAM-13, Pisa, Italy, 20-22 May 2019

* jean-pierre.birat@ifsteelman.eu
} 
par Michel Foucault en 1967 pour décrire un espace clos, dont les frontières marquent une discontinuité en termes de comportement : une prison ou un monastère sont ainsi des hétérotopies. L'économie circulaire (EC) est un concept essentiel de la transition écologique, tiré par une série de forces motrices convergentes, économique, écologique et politique. On la décrit comme un basculement vers un mode de production circulaire en remplacement du «modèle linéaire» mais aussi comme une expression à la mode pour parler d'efficacité matière, de règle des 3-R, de zérodéchets, de conception au plus juste (lean design) et de conception frugale ou comme reformulation de l'EC par la fondation Ellen Macarthur comme défit sociétal et nécessité éthique. Les producteurs de matériaux aiment à dire qu'ils pratiquent l'économie circulaire depuis bien avant que l'expression n'ait été inventée, donc à la Monsieur Jourdain! Dans cette publication on décrit l'économie circulaire comme un palimpseste et une hétérotopie, pour utiliser les métaphores, s'il ne s'agit que de cela, comme un révélateur des dimensions les moins évidentes de l'EC. Un palimpseste est un parchemin ou un papyrus, qui est utilisé plusieurs fois de suite pour recevoir des textes successifs. Les matières premières secondaires sont comme des palimpsestes, parce qu'elles sont récupérées d'un cycle de vie antérieur et réutilisées dans une nouvelle vie: un nouvel artefact fabriqué à partir de cette matière première est comme un texte écrit sur ou avec cette matière - une métaphore de l'écriture aussi utilisée, mutatis mutandis, dans des expressions comme impression 3-D ou scribing laser. Quelques particularités de ces métaphores appliquées à l'EC : un palimpseste peut être réutilisé plusieurs fois, de même qu'un matériau peut être recyclé plusieurs fois ; le concept de palimpseste postule que le parchemin est d'une certaine façon plus important que le texte qu'il porte, donc que le matériau est de la même façon plus important que les objets qui les incorporent ; les palimpsestes étaient utilisés avant l'invention du papier et, de la même façon, l'économie circulaire était le modèle de base de production avant que la production de masse de produits de consommation bon marché n'impose le modèle dit linéaire; un palimpseste conserve une mémoire fragmentaire du passé, de la même façon qu'un matériau recyclé maintient un lien avec le passé, par sa teneur en éléments résiduels. Des exemples d'hétéropie sont une prison ou un cimetière. L'économie circulaire définit un espace dans lequel un certain matériau ou élément existe sous différents avatars, personnifications et réincarnations, ce qui peut être analysé comme une hétérotopie. C'est une métaphore plus complexe que celle du palimpseste, mais qui est potentiellement plus riche. Foucault a défini des critères pour définir une hétérotopie et on peut les utiliser pour analyser la métaphore : particulièrement le fait qu'une hétérotopie est soit un espace d'illusion, soit un espace de perfection. Ces analyses sont originales parce qu'elles proposent une hybridation entre des concepts liés soit aux matériaux soit aux $\mathrm{SHH}$, ce qui les place à la frontière des thématiques matériaux et société, au cœur des explorations des conférences SAM.

Mots clés : économie circulaire / efficacité matière / cycle géo-bio-chimique / palimpseste / hétérotopie / métaphore / matériaux / SHS

\section{Introduction}

To explain how materials and society work and interact together, each expert calls first on his own core discipline but also explores less familiar fields, beyond his immediate disciplinary borders. Thus, in LCA he mixes physics (mass and energy conservation) with economy, accounting and sometimes prices (LCC), with labor regulations (SLCA) or with public health matters, epidemiology and toxicology for example. When the expert questions the basic nature of his understanding of time and space, he may cross the disciplinary borders and actually change discipline, like move from LCA to MFA [1]. Hard scientists tend to relate to hard science, but more rarely to soft, social sciences.

Our purpose here is to highlight some of the features of the Circular Economy (CE), an important concept adopted in the context of the Ecological Transition by a broad set of stakeholders, by referring to words that belong to utterly different areas of human thought, namely history and philosophy (Michel Foucault). This should hopefully help us discuss the $\mathrm{CE}$ in an original way because of the otherness of these cultures, compared to the culture of the CE community.

We will focus here on two specific words, palimpsest and heterotopia. A palimpsest means a manuscript written on an older document, the text of which had been erased; it was a practice in Europe during the Middle Ages. Heterotopia means an enclosed space, separated by physical or virtual barriers and where special rules apply: it stems from a philosophical enquiry about the nature of space, which was a preoccupation of Foucault at the time. The first word is widely used outside of historical circles, while the second only belongs to the abstract vocabulary of philosophy. We will start by reformulating what is the Circular Economy before developing the insight that each metaphor, palimpsest and heterotopia, brings to the understanding of the $\mathrm{CE}$.

\section{The Circular Economy}

The Circular Economy is a concept connected to Sustainable Development and to the age of Transitions ${ }^{1}$ that is under way [2]. There are many definitions of the CE, more than 300 according to Johnson [3]. The politically-correct definition of the Ellen MacArthur Foundation [4] says: "what is a Circular Economy? A framework for an economy that is restorative and regenerative by design". For our purpose here, we would like to stress that the $\mathrm{CE}$ is an ethical principle, adopted by most society stakeholders,

\footnotetext{
${ }^{1}$ Some people have even posited that a "grand transition" is under way, of which the ecology, the energy, the digital, the epidemiological or the food transitions constitute only the tip.
} 
international organizations, regional or national governments, businesses, NGOs and even moral and religious leaders [5]. It was even raised to the level of constitutional principles in some countries. It stresses the rules that we should follow, collectively, in order to preserve the wellbeing of people on the planet, today and in the future. Speaking about the CE does not speculate about whether it is possible to completely achieve material circularity or if it is only an ideal. It does not speculate either about whether it is possible to pass on a planet to future generations, where they will be able to live reasonably well: the realism of this pact of the present (generations) with the future (generations) is far from obvious. The Circular Economy and, actually, the whole framework of Sustainability constitutes an ethical or a moral compass to direct society towards less destructive practices and more "restorative" and "regenerative" ones. There is also, in the background, the idea that society should strive to function in the anthroposphere like nature does in the biosphere, a concept that lies at the root of industrial ecology, which is itself a metaphor of natural ecology.

The core physical entities that govern the natural world are time, space, energy and matter ${ }^{2}$. Energy and matter are conservative in a closed system, according to thermodynamics, and Sustainability is in effect saying that our world, Planet Earth, is finite, "closed", and that society should organize to live with this constraint, which, it seems to posit, is similar to a physical law ${ }^{3}$. The Club of Rome said more precisely that a subset of the Earth system was finite, namely energy and materials resources [6,7].

The usual formulations of the CE follow from these considerations:

- reuse and recycle, but also reduce - the 3- $R$ rule;

- the 3 -R rule should be implemented in the design of new products, lean design (less matter) but also frugal design (less variety of substances/materials/elements, especially critical or strategic ones);

- waste should be eliminated, in industry, where it is large in volumes ${ }^{4}$, but also in households and cities. This is the

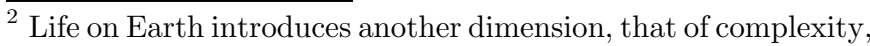
which probably operates at a larger scale in the inner workings of biology and evolution than it does in physics. These 5 quantities might be seen as the five elements which are at the core of our contemporary worldview, a modern version of the 5 elements of the Ancient.

${ }^{3}$ Planet Earth, however, IS NOT a closed system. Its energy comes entirely from the Sun, either directly (insolation) or indirectly, stored in the fossil fuels that have accumulated solar energy collected by plants in the geological past. This model itself is also over-simplistic, as nuclear fuels do not originate from the sun but are older than it is, etc. The whole universe and its cosmological past have to be included in the narrative. Then, maybe, we will have reached a system which is truly closed, even if it has been expanding...

${ }^{4}$ Waste from industry includes the waste from mining. This waste cannot be reused or recycled at a high rate. Therefore, a better definition of "zero waste" should be implemented: zero waste should include waste dumped of in monitored landfills, thus managed in a sustainable and safe way (dams to store mining sludge do not match this definition).
}

target of "zero waste", which industries are keen to advertise, but also of "curbside collection" of household waste, more accurately described in French by "tri sélectif';

- value chains, therefore, should close ("closing the loop") and the industrial organization of production should move from the so-called linear model to the circular model;

- this goes one step further when new organizations of society emerge and are encouraged, such as sharing rather than buying consumer goods, and other cooperative behaviors.

These CE rules address society at the level of whole economic sectors, of individuals (households, individual behavior and lifestyle), of territories (cities, countries and the world as a whole) and of economic and political organizations.

The CE is often seen as the equivalent for raw material resources of the energy transition for energy resources: the coherence of the two approaches is not ensured, however, as the expression of "resource paradox" related to the energy transition points out [8]. E-mobility, for example, calls on scarce elements to produce batteries, electrical motors, etc. so that the environmental footprint of e-mobility depends more on the construction phase of the equipment than did older, fossil fuel-based technologies.

There are other issues relative to the $\mathrm{CE}$ that have emerged.

Should circularity be a target, no matter what, or should some argument relative to an environmental footprint be used to decide whether circularity should be on the agenda in a particular situation or not? I remember an advertisement in Berlin claiming: "We are recycling our airport", which was clearly a metaphor, and there is a strong push in the area of climate mitigation to implement the recycling of $\mathrm{CO}_{2}{ }^{5}$, a potential technology called CCU or CCSU. Should $\mathrm{CO}_{2}$ always be recycled-or airports, for that matter?

Materials producers [9] have claimed that the historical model of production was always the circular model and that the linear model was only introduced in the 20th century as a consequence of the $3 \mathrm{rd}$ and the 4 th industrial revolution. This is not simply a quarrel about "who was first", but an argument to the effect that most materials have been organized for recycling, reuse and lean design since long before the word of "Circular Economy" was invented in the academic literature.

Material producers also point out that [10]:

- materials are used for long periods of time and thus might remain in the economy as a stock-in-use before they can join the circular merry-go-round: for example, $50 \%$ of steel production is used in construction and civil

\footnotetext{
${ }^{5}$ Into carbon, fuels or organic molecules. The small print assumption is that the energy necessary for doing this chemical reduction of carbon dioxide would be renewable energy and that they it would substitute for fossil-based fuels. It thus ought to be presented as a solar-to-fuel production route, for example, rather than as the recycling of $\mathrm{CO}_{2}$.
} 
engineering, where the lifetime is of the order of 70 years. Therefore, it is not as urgent to recycle a building as a smart phone;

- materials can be recycled once, or several times, or indefinitely. The environmental benefits of indefinite recycling, for example, are almost an order of magnitude larger than single-step (once-through) recycling [11];

- this is true of metals, ferrous and non-ferrous, of glass, paper and, to a lesser extent of plastics and concrete. The jury is still out on new materials.

The circular economy concept is continuously evolving: the new "kid-on-the-block", today, is the bio-circular economy.

\section{The palimpsest as a metaphor of the Circular Economy}

This section explores how the concept of palimpsest can help refine our understanding of the Circular Economy.

A palimpsest (from Latin palimpsestus and old Greek $\left.\pi \alpha \lambda i \mu \psi \eta \sigma \tau \varsigma^{6}\right)$ is a manuscript written on a papyrus or, more often, a parchment, which the copyists in the Middle Ages had erased and covered with a new text.

The word palimpsest is also used metaphorically:

- «toute oeuvre est un palimpseste» [12] ("any work of art is a palimpsest');

- «L'oubli n'est autre chose qu'un palimpseste. Qu'un accident survienne, et tous les effacements revivent dans les interlignes de la mémoire étonnée» [13] ("Oblivion is in effect a palimpsest. When something unexpected happens, all the forgotten items resurrect between the lines of a puzzled memory");

- «C'est là un édifice palimpseste, où les courants artistiques se juxtaposent et se recouvrent au gré des siècles» [14] ("this building is a palimpest, where artitistic currents are juxtaposed and overlap over centuries");

- in our modern, paperless world, most digital storage devices are palimpsests and indefinite ones: flash memories for example can be written over, again and again.

The point we want to make is that scrap, or recycling, or the Circular Economy can be described metaphorically as a palimpsest. Steel scrap, for example, originates from a former economic good/artifact, transits as scrap, a secondary raw material, and ends up in a new good. The function of steel changes (artifact 1 and then artifact 2) but the material and its social value (use) carry on, endureand so do the socio-systemic services that it provides [15].

\subsection{How many times is a palimpsest reused, how many recycling steps?}

A palimpsest can be used once or several times. This is true of parchments and texts but also of canvases and paintings. In the scriptoria of monasteries, during the Middle Ages, there was thus a double economy of books, some written on

\footnotetext{
$\overline{{ }^{6} \text { Meaning something that }}$ one scratches in order to write on it again.
}

virgin parchment and others on reused ones, the palimpsests - an echo of the distinction between primary (virgin) and secondary raw materials.

\subsection{What about materials?}

Most materials can be recycled several times, sometimes indefinitely: therefore, the palimpsest they constitute will play out again and again, sometimes indefinitely.

This distinction between single-step and multi-step recycling has received attention from the metal community, even though it is not so visible in the more general literature related to the $\mathrm{CE}$ [11]. Indeed, multi-step or indefinite recycling brings clear environmental benefits, compared to single step recycling.

Figures 1-3 show what indefinite recycling means in practice: the material can be used over and over for the same applications only part of it is recycled (in the example $80 \%$, a conservative value for steel), the rest being lost or dissipated to the environment (creation of waste); after 10 cycles $^{7}$, the benefit is almost nil. On the other hand, until it is fully dissipated, the initial ton of material is used 5 times, a very significant material saving. The (reverse) metaphor is that the same parchment can carry the message of several books.

Recycling has other benefits, beyond materials efficiency. Figure 4 shows how it improves energy efficiency in the case of steel recycling: the argument is that the recycling production route, based on the EAF rather than the Blast Furnace, saves about $2 / 3$ of energy at each step. Figure 5 shows the effect on $\mathrm{CO}_{2}$ emissions: indeed, the EAF route cuts emissions by about $3 / 4$ th, so that the recycling steps beyond the first use weight only $1 / 4$ th of it. Other indicators, for example in a complete LCA, would show the same trend: virtually all environmental indicators are significantly improved and the effects accrue with multistep recycling. It wears off, however, after several cycle, since the recycling rate is always less than $100 \%$.

It was argued that this kind of presentations plays around with temporality, because the cumulated effects are aggregated together, even though they take place at different times: this, however, is more a reflection on the complexity of taking time on board in methodologies like LCA and MFA than a radical criticism of the presentation.

The arguments made until now have focused on materials that can be recycled several times without loss of properties. We now address the case of a material, which is downcycled, i.e. recycled but in less demanding applications than its initial use: for example, recycled aluminum, which contains a mixture of pure aluminum and various alloys, is reused to make car engines, the only application where alloying elements are not penalized, rather than cans or car bodies. Figure 6 shows what this implies, in a scenario where there would be a major switch from using steel to using aluminum in automobiles [16]. The generation of aluminum scrap will keep increasing as the growing amount of aluminum reaches the end of life of the cars in which it is embedded, but the market for car

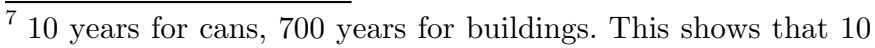
cycles of recycling is a very large number, too large in many cases!
} 
Moi, bientôt,

je serai une voiture de course.
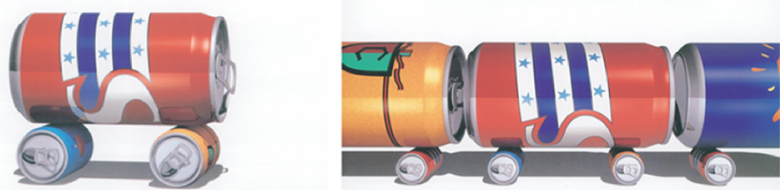

Fig. 1. Advertising for steel can recycling, emphasizing its indefinite nature (left: "When I grow up, I'll be a racing car"; right: "there's no doubt that, tomorrow, I'll be a High-Speed Train").

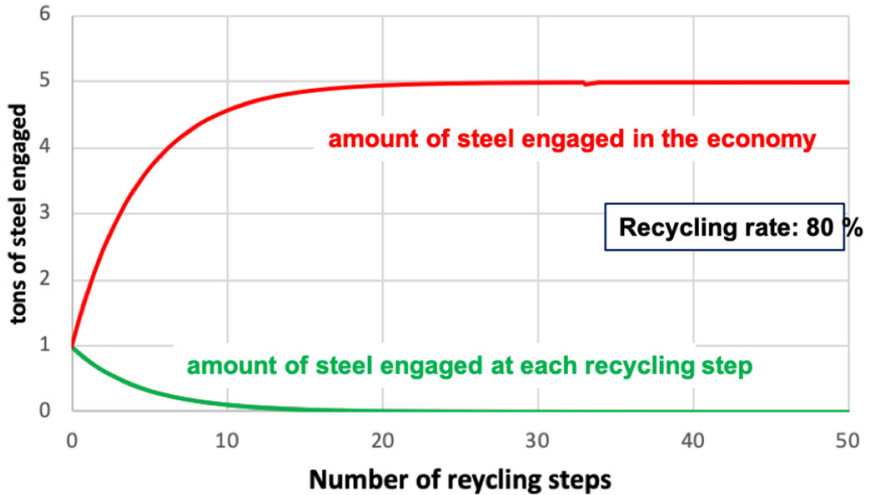

Fig. 3. Material resource efficiency (material saved at each recycling step).
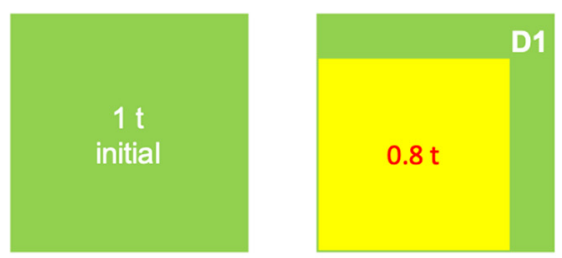

Recycling steps
1

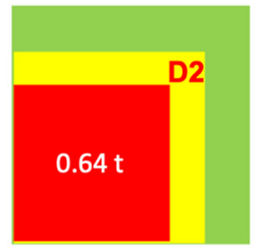

2
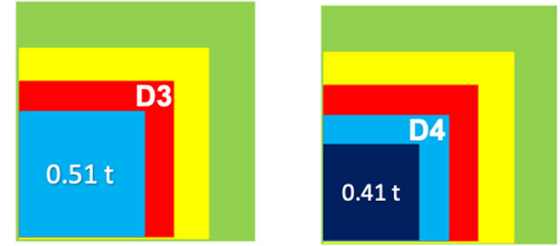

3

\section{4}

Fig. 2. Schematic representation of multi-step recycling. The number of steps in this case is 4 . The initial steel is shown as "INITIAL" and the amount available at each step decreases with time (recycling rate $=80 \%$ ). At each recycling step, some steel is not recycled because of dissipation to the environment. Material dissipated at the 1st recycling step is shown as "D1", at the 2nd step "D2", 3rd step "D3" and 4th step "D4".

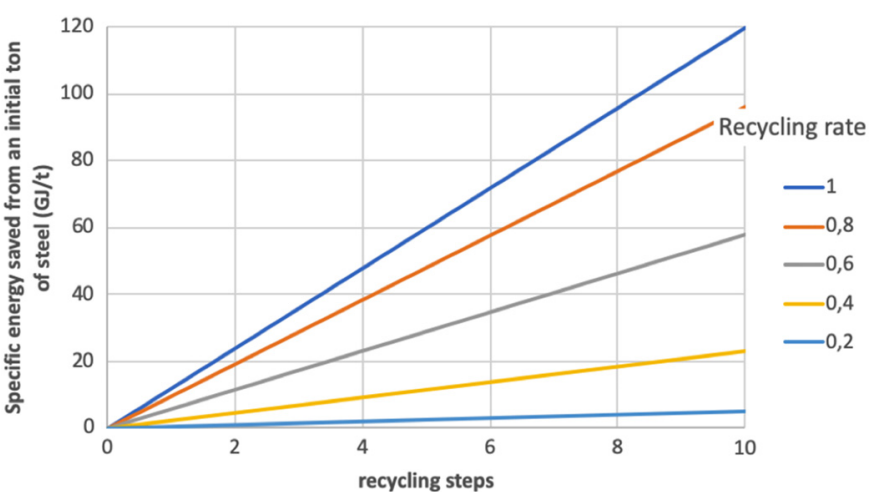

Fig. 4. Energy efficiency (cumulated energy saved) as a function of the number of recycling steps and of recycling rate $(\mathrm{R})$.

engines will not increase as fast: a cross-over takes place, according to the model in 2024, when demand becomes less than supply: therefore, even if aluminum keeps being recycled, then it will not be used and probably not be collected but go to waste; this shows that, even if the collecting rate increases, the actual recycling rate will drop (Fig. 7). In truth, this will probably cause the recycling players to look for new solutions, either to dilute the scrap in virgin metal or to purify it. Moreover, taking the

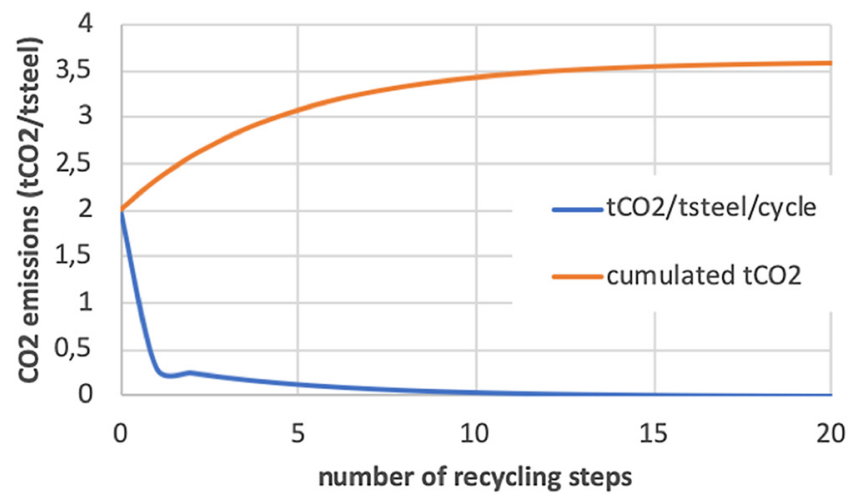

Fig. 5. Reduction of $\mathrm{CO}_{2}$ emissions as a function of recycling rates (emission at each cycle and cumulated emissions due to the initial ton engaged).

example of aluminum may be seen as unfair as, most probably, if the trend to make more alloyed steel continues [17], then the problem will also arise for steels, eventually. But the lesson is that the benefits of downcycling are much less than those of multi-step recycling.

Therefore, the CE will be more rewarding if the materials that eventually enter the recycling realm can be recycled several times. If recycling takes place only once, which is more or less equivalent to downcycling, then the 


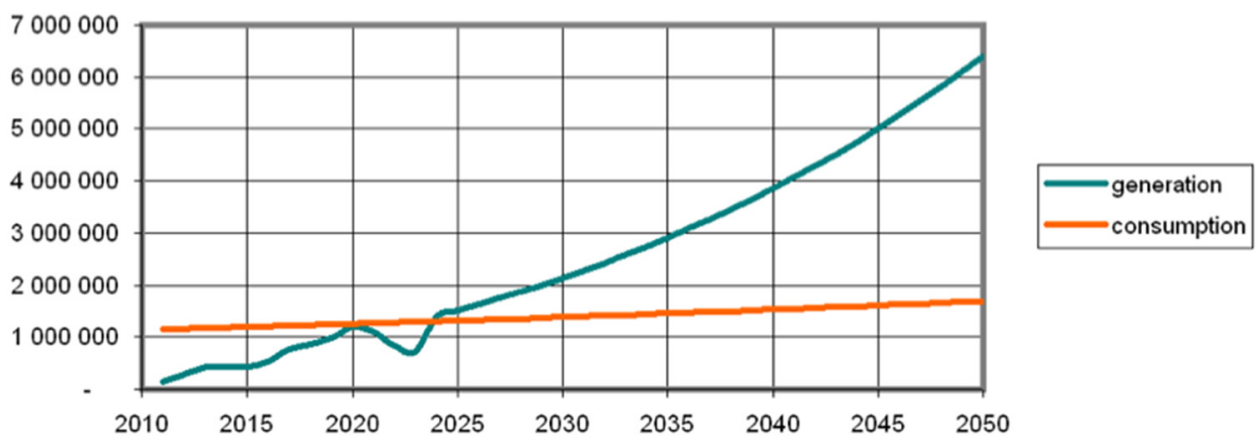

Fig. 6. Generation of scrap of a metal which is downcycled (blue green) and evolution of demand for polluted scrap (orange).
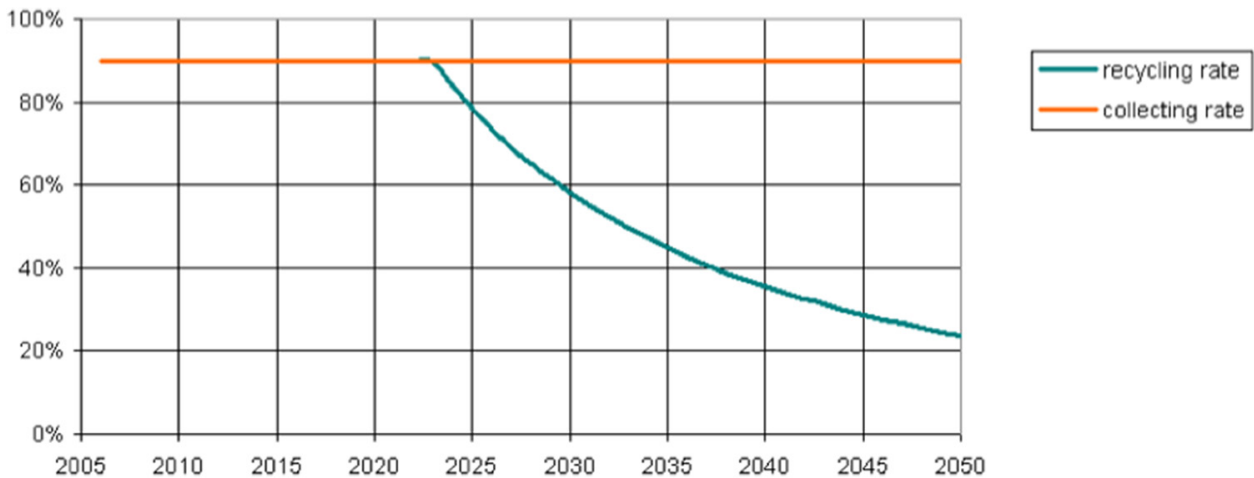

Fig. 7. recycling rate and collecting rate, two distinct concepts in the case of a material that is only recycled once, because of downcycling.

CE does not always bring benefits in terms of resources or emissions, thus in terms of a generalized environmental footprint, but only generates more waste. This also means that the CE practice should not be pursued indefinitely in the particular case of Figures 6 and 7 .

Similarly, the copyist monk will not reuse an old book that cannot be properly erased of its former content! Or he will use it in a downcycled manner, as a scrapbook ${ }^{8}$ for example.

Regarding the CE, this discussion brings forth the need to better include temporality in the definition of circularity, i.e. to resort to the analogy to a helix or a spiral rather than to a circle (cf. Fig. 12).

\subsection{What is more important, the parchment or the book, the material or the artifact? Narratives and storytelling...}

The concept of the palimpsest posits that the parchment is somehow more important than the text that is written on it, because parchments are rare and more expensive than the "labor cost" of the copyists. This would mean that a material is more important than the artifacts that are made of it. This is indeed true over the long term, as the material or the parchment transcend the short lifetime of the artifact or the text.

On the one-hand, artifacts are short-lived, designed as they are for a definite, preset lifetime: they will be

\footnotetext{
${ }^{8}$ Note the use of scrap in that composite word!
}

replaced by new, improved versions of the same good: as a matter of fact, the new versions are already ready to be launched on the market when the marketing division decides it is time to do so. A product follows an $S$-curve (technology life-cycle) and new products are launched when that curve has reached its plateau and the product has exhausted its benefits for the business. Consumer goods are perishable and disposable. Critics of this practice claim that it is planned obsolescence. Anyway, an old cellular phone is soon forgotten, except in vintage movies!

On the other hand, materials are perennial, enduring, lasting, all the more so as they are recycled several times. In our society, however, materials are hidden inside artifacts and the user/consumer is not aware of them explicitly because the storytelling of advertising carries the message of consumer goods producers. (what is the difference between different metals or metals and plastics? O between a concrete, a steel or a wooden building, etc.?). However, there is another narrative that relates to materials and tells how they constitute the backbone of the anthroposphere and how they perform this role all the better that they are reused and recycled more and more [18]. This latter story is less audible in the general public than the former one, because there is no clear monetary value associated to recycling.

Indeed, this role of materials is an externality in our market-driven society. A conceptual solution for internalizing the recycling of materials is to refer to the eco-socialsystemic services (ESSS) that they provide, which are 
similar to the ecosystem services of biodiversity. In this theoretical framework, ESSS have a value, in effect a social value.

Like palimpsests, materials are perennial, a distinct feature of their contribution to the CE. This brings up the need again to include time in the definition of the CE. This is future time, i.e. the time of the future generations of which Sustainability is prolix about in its own storytelling yarn. It is a time counted along the axis of the helix (cf. Fig. 12) rather than the circular, angular time of the life cycle.

\subsection{The palimpsest as a cyclic model, the CE as a recurrent one}

Palimpsests were the original models for recording written documents, long before books printed on paper became ubiquitous. Note also that the digitalization of writing has made the concept of palimpsest alive again: a final manuscript, an article or a book, is usually the outcome of very many different versions that are copied over the former ones, which are erased in the process. Screens magnify this effect even further!

The same is actually true of materials, if the long historical time is considered. The model was long lifetimes and reuse - several times, indefinitely - for materials like stone $^{9}$, pottery/ceramics/glass ${ }^{10}$, fabric (clothes) or metals $^{11}$, since the Paleolithic until the 21st century. The socalled linear model, which is at the core of the criticism of the market organization that gave rise to the $\mathrm{CE}$ model, is a rather recent practice related to mass production, to the globalization of markets and to the increasing complexity of consumer goods in terms of the number of different comaterials that they incorporate. Now the emphasis of policymakers is on the circular model: consciously or not, they are reverting to an old practice and somehow reinventing the wheel.

As pointed out earlier in this article, materials are extensively reused and recycled. When the matter is paper, then recycling is analogous to a palimpsest, even if the technology is different from the scrapping and erasing of parchment that monks used.

Thus, the Circular Economy is actually a recycled concept, which is somewhat ironic! Similarly, the palimpsest is an enduring one, not confined to the practices of the copyists in the Middle Ages.

Circularity is a recurring model, with streaks of linearity. This depends on the value associated to each model, on the price of raw materials and on the ability of the market price to internalize environmental externalities.

\footnotetext{
${ }^{9}$ The hand axes (bifaces) of the Paleolithic and the various tools that followed for the next 50 centuries until the invention of metals in the final Neolithic.

${ }^{10}$ Pots, amphoras and tableware.

${ }^{11}$ Jewelry made of precious metals but also weapons and tools made of copper, bronze and iron. More recently, pots and pans were part of the inheritance of children or of the dowry of women at their wedding. So was a set of linen for bed and table, meant to last for a whole life.
}

Now, it becomes clear that the concept of Circular Economy is used in several rather different contexts. Most people, including the policymaker, think initially of consumer goods when they discuss the CE. But the CE has been proposed and imposed as a "new" model to materials producers and they are answering that it is not new and that they have been practicing it since the beginning of times. The truth is that the extent to which the practice is common depends on the material and on the intimacy of the mixture of materials, very complex and sophisticated in modern industrial artifacts. Metals, glass and paper are much more recycled than plastics or concrete. However, if pure metals are easily recycled, association of metals or alloys are most often lost: thus, the Circular Economy is in this case only partial, for the time being - because other solutions are still economically "reasonable".

\subsection{Hidden text in a palimpsest, purity of secondary raw materials}

A palimpsest keeps a fragmented memory of the past: experts can sometimes recover part of the erased text or of a prior, hidden painting.

Similarly, recycled material maintains a link to its past lives, though its composition in tramp elements for example (vocabulary used in the case of steel scrap). This may limit the number of times the material can be recycled, in the same way as the number of superimposed texts is limited by how well the older ones are erased.

There are several ways for materials to deal with this situation:

- some tramp elements disappear when the material is reused: this takes place in the melting furnace during the oxidizing period of refining, where elements less electronegative than the metal report to fume or slag and thus are either lost, dissipated, landfilled or confined in waste that will have to be recycled to recover them. Other elements stay alloyed in the metal: this is true, for example, of $\mathrm{Ni}, \mathrm{Co}, \mathrm{P}, \mathrm{S}$ in the case of iron, of Fe in the case of copper, etc. Some elements are partly removed and partly retained, like $\mathrm{Cr}$ or Mn in steel;

- the remaining tramp elements can be diluted by diluting the "contaminated" scrap in purer metal, a trend which leads to a plateau after several recycling steps rather than to a continuous pick-up. This is the case of the recycling of tinplate of steel, for example [19]. Figure 8 shows the plateau reached when the tinplate is added in the BOF, where it is diluted in virgin hot metal, and the continuous pick-up in the case of the EAF, where the dilution does not take place;

- the tramp element pick-up can indeed increase with time and this depends on the purity of the scrap, often on the care given to the sorting of iron and contaminating elements like copper, as shown in Figure 9 [20]. Thus, a solution is to bring the contamination of scrap down, by using comminution, separation and sorting techniques, and, sometimes, pyrometallurgical or hydrometallurgical purification;

- this shows why the combination of dilution and better preparation of scrap, ensured by the existence of a scrap 


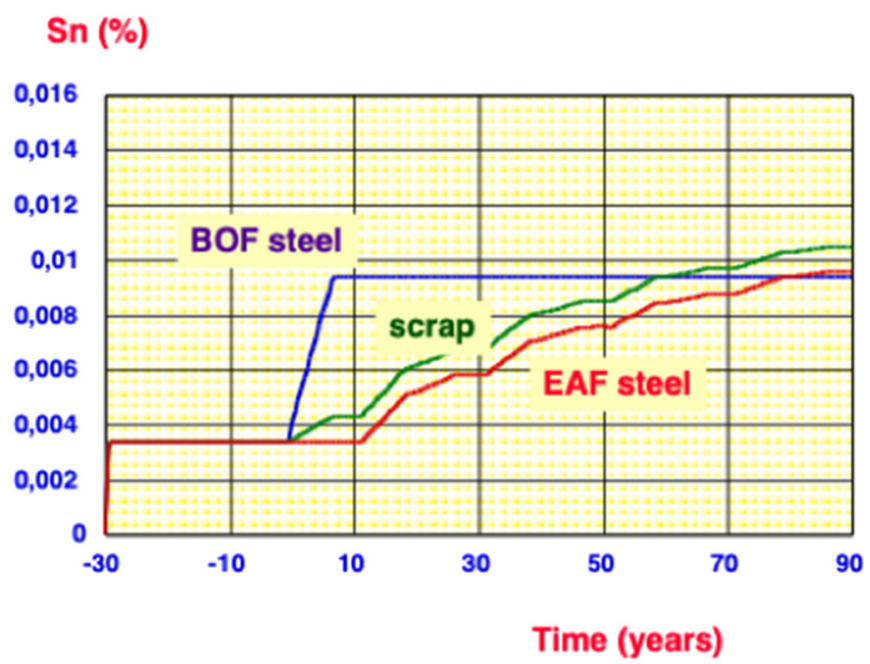

Fig. 8. Figure shows the tin pickup in the resulting steel, with dilution (BOF steel) or without (EAF steel).

referential, which specifies purity in tramp elements, has been able, over the last 20 years, to keep the level of tramp elements from increasing in steel;

- a more radical strategy consists in segregating alloyed metals and in recycling them to produce exactly the same grade that they originate from. This is common practice for $\mathrm{Ni}$-based stainless steels, because it is non-magnetic compared to carbon steels and therefore easy to sort out and there an attractive price differential for doing this. The same is true of tool steels (alloyed with elements like Co, W, etc.). Aluminum could (does) use the same technique to recover alloyed aluminum from car body applications.

Residual elements can also help trace the origin of raw materials to a specific mine and thus recall their original lives, several lifetimes ago; much like reading the hidden text on a present version of a manuscript, written on a palimpsest.

\subsection{Conclusion on palimpsest and the CE}

What the palimpsest metaphor brings to the CE concept is a deeper intuition about the role of time in the $\mathrm{CE}$, something similar to the discussion of temporality in LCA and MFA methodologies [21]. The crux of the discussion is that there are different times to which the Circular Economy relates: the calendar time, i.e. the time of physics, the arrow of time, and the circular time of "the loop" that the CE wants to close. These two concepts of time are independent, as if they were the eigen values of a multidimensional time. This goes somewhat beyond standard physics, but not beyond the discussions of time by philosophers (e.g. Augustine [22]) or other social scientists [23]. In the palimpsest metaphor, there is the time of the parchment and the time of the various successive manuscripts.

In a standard discussion about the CE, the focus is mostly (only?) on the circular time.

\section{The heterotopia metaphor of the Circular Economy}

Michel Foucault introduced the concept of heterotopia in a conference he gave in Paris, in 1967, to architecture students [24,25]: he was addressing young people, whose job would be to create spaces for people to exist socially, and he tried to propose a new approach to space and to spatial thinking. In his own inquisitive and brilliant way, he wanted to come up with a truly modern idea of space beyond that of emplacement ${ }^{12}$ ( $F$ : localisation) of the Middle Ages, of extension ( $F$ : étendue) in the Renaissance (Galileo) and of divergent sites ( $F$ : emplacement) in the mid-20th century. His intuition was that between virtual places like utopias, which do not physically exist, and the real world, there were categories of space that participate to both, being at the same time part of the world but following different rules than the social rules adopted elsewhere-thus being "utopias that have become real", as he said. These are enclosed places, such as a graveyard, a boarding school, the military service, a mirror, a wedding night, a psychiatric hospital, a retirement home, a theater, a movie theater, a garden (and a carpet!), a museum, a library, a brothel, a jail, a barrack, hammams and saunas, colonies, ships and boats ${ }^{13}$... It is clear that although they entertain close connections with the world at large, they function according to their own special rules. He coined the word heterotopia, "other spaces", to designate them.

Michel Foucault proposed six major features to characterize heterotopia: (1) they exist in all cultures in different forms, (2) their rules change with time, (3) they can consist of several spaces, (4) each one being a heterotopia, the connection with time is dissonant so that a heterochronia exist in the most interesting heterotopia (think of the cemetery!), (5) the heterotopia is both open (there is a flow from the outside to the inside) and closed (there are gates, which can be shut close) and, finally, (6) heterotopia reflect the features of society by providing either spaces of illusion or spaces of perfection.

We will try different ways to make use the concept in relation to the Circular Economy.

\subsection{First attempt}

The first way relates to the CE as a whole and we posit that the $\mathrm{CE}$ is a heterotopia. Indeed, to demonstrate that, we can check if a heterotopia meets the six criteria of Foucault:

- it is related to society and to the anthroposphere in a very general way (everybody is more or less invited to pitch in);

\footnotetext{
${ }^{12}$ The translation of Foucault's vocabulary given in [24] is used here, with its imperfections.

13 «Le navire, c'est l'hétérotopie par excellence. Dans les civilisations sans bateaux les rêves se tarissent, l'espionnage y remplace l'aventure, et la police, les corsaires》. "A ship is the emblematic heterotopia. In civilizations without ships, dreams dry out, spying replaces adventure and police, the privateers".
} 

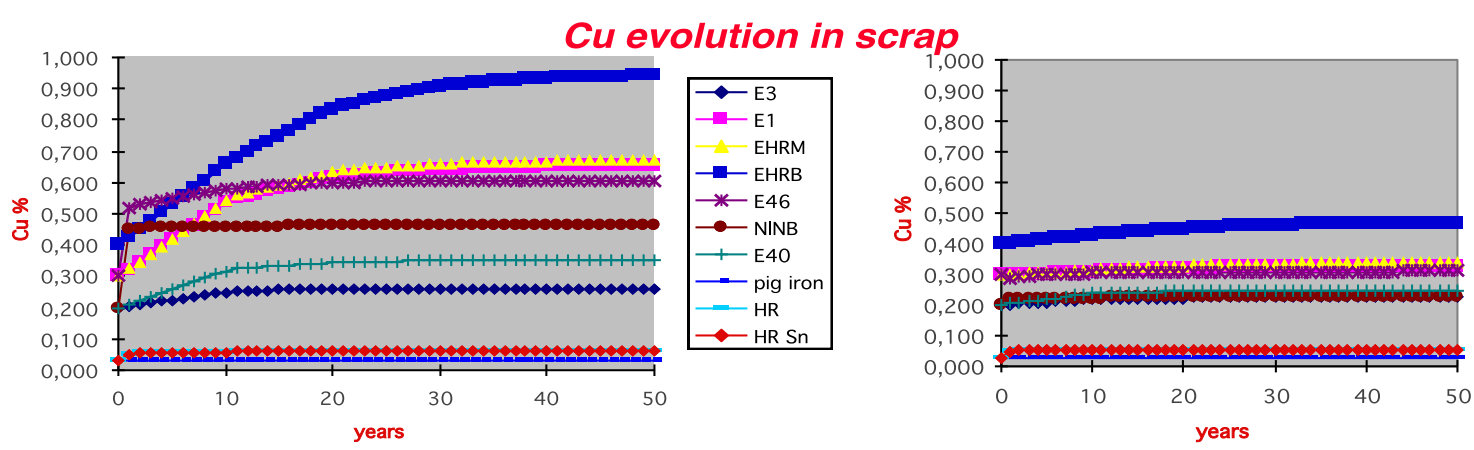

Fig. 9. Evolution of copper content in the steel scrap with two purifying policies (left: lax, right: strict). Each curve shows a category of scrap according to the prevalent standard at the time).

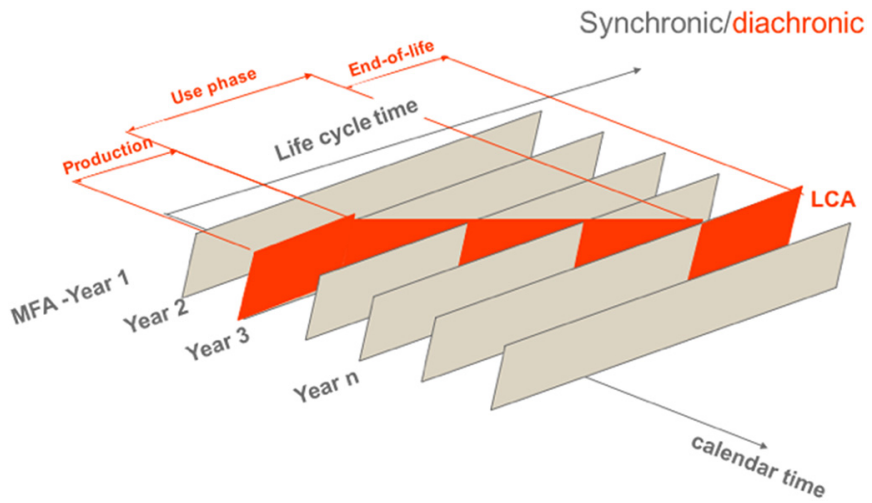

Fig. 10. Temporalities in LCA and MFA: a comparison [1].

- its rules have changed with historical times, from the paleolithic to the curb side collection implemented in modern cities, but it is basically the same "space": cf. the point made under Section 3.3;

- the Circular Economy exists in different spaces: recycling of waste, recycling of materials, recycling of consumer goods, maybe also recycling of $\mathrm{CO}_{2}$ or of an airport. This diversity of points of application is what initially created confusion in understanding what was the basic meaning of the CE. The answer now is simple: no confusion, the $\mathrm{CE}$ is indeed a heterotopia, with all of its attributes!;

- the CE entertains subtle and complex connections with time, as discussed at length in Section 3: circular time, linear time (arrow of time), helicoidal time. The CE is both a heterotopia and a heterochronia;

- the CE lets waste in, but only the proper type of waste, suitable for a new life;

- finally, it is a space of perfection, the world where the Circular Economy is fully deployed, the ideal that the CE proposes to society, or, conversely, it is a space of illusion as indeed this ideal will mostly remain out of reach.

\subsection{Second attempt}

A slightly different way of defining the Circular Economy Space (CES) is to see it as a space where the different avatars and reincarnations of a particular material coexist

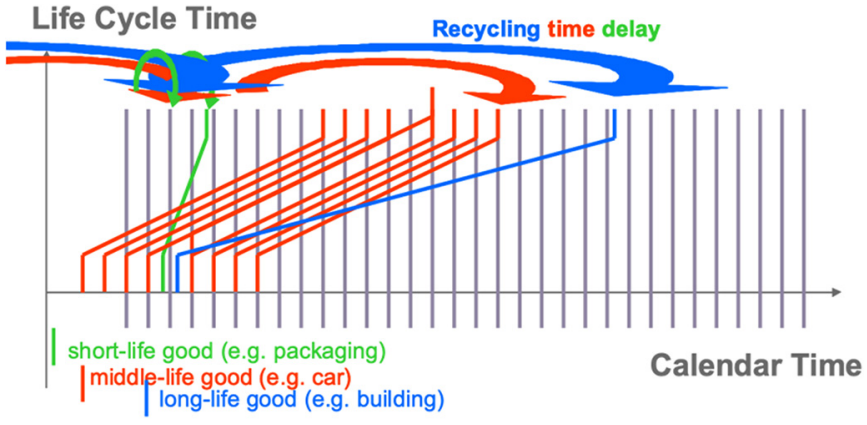

Fig. 11. Temporalities in LCA and MFA, with lifetimes of different durations [1].

and then to aggregate the spaces of the different materials together. They do not all exist at the same time or in the same place: we have to imagine the CES as a dynamic system, as shown in Figure 10 - where a representation of the difference between MFA and LCA is proposed.

One should distinguish between the synchronic and diachronic flows of events or use the analogy of fluid dynamics, where there is the option of describing the equations of flow, either with Euler coordinates (looking at the flow as it goes by an outside observer, as in MFA) or with Lagrange coordinates (looking at the flow from the standpoint of an observer, who is riding along the flow itself, as in LCA). The CES encompasses this total extension across space and time, thus constitutes a mixture of heterotopia and heterochronia, one of the key criteria of Foucault. Granted, the concept is somewhat more abstract than his original definition, but only at the margin.

The matter of time is more complex, as different artifacts have different lifetimes, as shown in Figure 11: therefore, there is in effect an infinity of life-cycle times.

A variant of Figure 10 is shown in Figure 12, where the cycle time is shown as a circle so that the overall representation is an helix.

What are the rules that apply to this CES? Not exactly the physical laws of normal space. Indeed, there is no conservation of matter in the CES, as some of the matter is bleeding out of the system, being either landfilled, or dissipated or lost: the CES is therefore not a closed system. Similarly, the system exhibits an environmental footprint, 


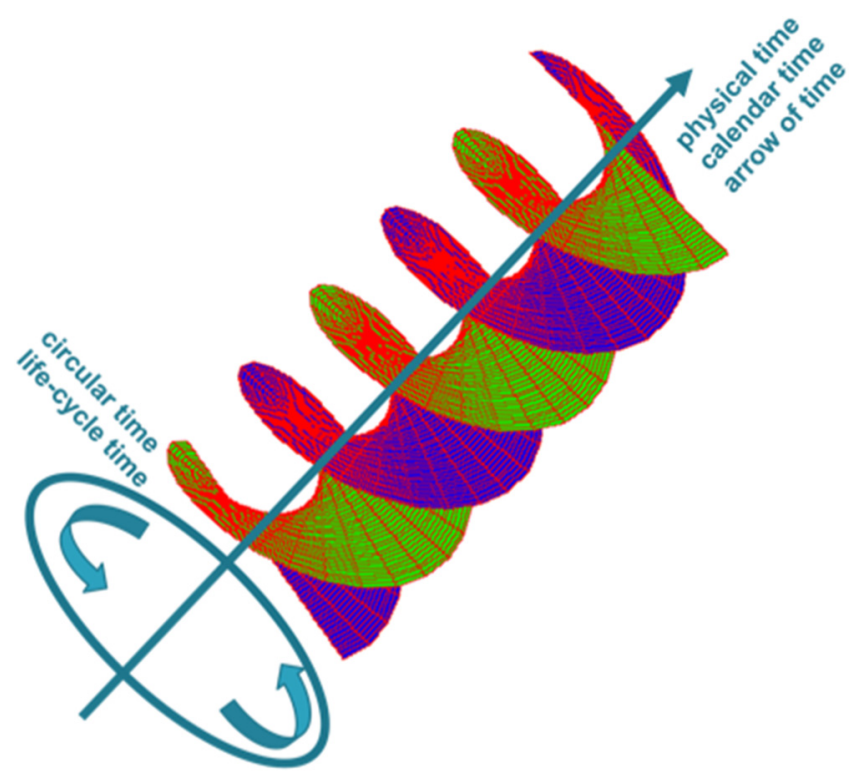

Fig. 12. Circular, linear and spiral times in the Circular Economy Space.

for example GHG emissions, that vary with the succession of life cycles and therefore is not a linear function of time (cf. Fig. 5). There is also an economic dimension to the $\mathrm{CES}$, in as far as the economic costs related to each cycle usually decrease, while a social value is generated: this social value measures the rationale for going ahead with the Circular Economy practice. These rules are different from the rules of the real world, again a Foucault criterion.

\subsection{More intuitions}

The CES exhibits other interesting features, in the way that different materials/substances/elements interact and how they are stored in various stocks, while they are not released back into a secondary raw material stream.

The discussion on the various materials present in the CES was carried out in Sections 3.3 and 3.4. There are major materials present in large volumes, which are already deeply involved in the Circular Economy, and minor ones, less volumetric, often associated with the major ones, but lost in the recovery processes: for example, iron in zinc or copper production, or copper in steel EAF production. The reason is that, although there is a social value in recovering these minor elements, the economic cost of doing it is too high, hic et nunc. Note, incidentally, that the technology is very often available, but the costs do not add up. We are again caught in a tension between different values, economic, environmental and social ones. Maybe the hierarchy between them, which in the real world gives priority to economics, would internalize the other values in the CES and thus show a path to resolving this conflict.

The matter of stocks is also important and interesting. Miners talk about reserves and resources. There are similar concepts in the CES: there are stocks of materials-in-use or MIS (material-in-stock, ferraille sur pied), hibernating stocks in the netherworld between MIS and secondary raw materials, and the anthropogenic mine (AM), which includes lost and dissipated materials ${ }^{14}$. As a matter of fact, if we use this concept of AM, then there is conservation of mass in the CES, contrary to what was said in the previous section. The anthropogenic mine becomes part of the CE resource but is left out of the $\mathrm{CE}$ reserve.

Thus, we feel that looking for the appropriate rules that apply in the CES leads to a more insightful exploration of what the CE concept encompasses, as far as materials are concerned.

\section{Conclusions}

In the present article, the concept of Circular Economy was discussed from the standpoint of materials, based on the argument that materials are the actual objects of that circularity, not the goods of which they are part, every now and then.

We have also used concepts proposed by various SSH disciplines - palimpsest and heterotopia - to help explore the $\mathrm{CE}$, in order to reach out beyond the usual approaches and narratives about the topic.

It turned out that both concepts are complementary and, indeed, can help propose and organize a rather coherent critical analysis of the $\mathrm{CE}$.

The concept of palimpsest was initially analyzed as a metaphor to describe the material that goes around in the $\mathrm{CE}$ : however, it became apparent that the CE was not simply a metaphor but constituted an actual example of a palimpsest. This made it necessary to question the temporality of the $\mathrm{CE}$ and the nature of time, when a consumer good is recycled but the materials it contained go back in the economy and often do it, again and again: time therefore, has a directional component, the arrow of time, and a circular one, life-cycle time, thus becoming no less than multidimensional. We were then led to question the value the CE brings: the CE is not simply an ethical goal, it does create value, economic, environmental and/or social, which can be quantitatively estimated. If it fails to do so in some particular case, then maybe one could dispense from following it, there and then, as a mantra. This is however the reason why, in many cases, the $\mathrm{CE}$ deserves to be an ethical principle, if applied within reason.

The concept of heterotopia is even richer. It designates a space in our real world, which is somehow separate from ordinary space and follows different rules from the common rules, social rules and even physical rules, laws.

It turned out that the CE is indeed a heterotopia, as it meets the six criteria exhibited by Foucault, when he came up with the concept in 1967. Most interesting is the fact that the CE is both a space of perfection, as indeed it represents an ideal that rises to the level of an ethical injunction, and a space of illusion, as bringing society to the level of this ideal is out of reach, or at the very least difficult to achieve.

One can proceed a step further and analyze the Circular Economy Space (CES) as a heterotopia, and thus become able to grasp its complex connection with time: in the process, we come up once more with the analysis developed

\footnotetext{
$\overline{14}$ This is one definition of the AM. There are others, which include hibernating stock and even MIS.
} 
from the palimpsest analysis, that of a 2-dimensional time. One can also refine the features associated to that space, i.e. economic, environmental and social values, and show that these values are consubstantial to the CES and therefore should not be taken as independent or contradictory - as they are, hic et nunc, in the real world, where economics takes precedence because the environment and many social dimensions remain externalities. More features of the CES are related to purity, to co-elements, to co-recycling. Last, for the time being, is the structure of the CES, where some matter flows, while other rests: the nature of the stocks, for example the anthropogenic mine, are a feature of the CES, akin to the reserves and resources of Mining engineering; in this model of the CES, waste has been totally eliminated and the conservation of mass reinstated.

The original statement made in the introduction, that everything is related to time and space was not simply a rhetorical argument: in the $\mathrm{CE}$, space and time are complex concepts and analyzing them in details leads to a better understanding of what is the true essence of the CE.

The present discussion reinforces the CE concept, as it shows some of the benefits it brings to society in an explicit, quantitative manner beyond the fact of being a moral compass. The article's argument also indicates that the concept of CE should not be used indiscriminately, but, like speed limits on the road, it should be implemented with some subtlety, particular by referring to materials more than it does.

This analysis is original because it hybridizes material and $S S H$ concepts. It thus fits in the exploration of the frontier between materials and society that SAM conferences are concerned about.

Now, if the scope of the circular economy is extended to the biosphere (Bio-Circular Economy) and not confined, as it is today, to the anthroposphere and the geosphere, then the discussion should be started all over again and other conceptual catch words could be used for this purpose, from the interface between SSH and Life Sciences.

Acknowledgements. This article uses results already published and developed during my tenures at ArcelorMittal Research or at ESTEP: I am grateful to my former colleagues there, particularly to M. Chiappini. The methodology used in this article is common practice in SSH, but much rarer in discussing scientific, engineering and policy issues: as an engineer, I learned a lot in this area by discussing with A. Declich and K. Birat.

\section{References}

1. J.-P. Birat, The greening of the steel industry, in: Gordon Research Conference, Industrial Ecology, Transforming The Use of Energy, Materials, Water And Wastes, August 17-22, 2008, Colby-Sawyer College, New London, NH, Faye Duchin (chair)
2. C. Afriat, J. Theys (sous la direction de), La grande transition de l'humanité, de Sapiens à Deus, FYP Éditions, 2018, $271 \mathrm{p}$

3. P. Johnston, M. Everard, D. Santillo, K. Robért, Reclaiming the definition of sustainability, Environ. Sci. Pollut. Res. 14, 60-66 (2007)

4. Ellen MacArthur Foundation, Available from https://www. ellenmacarthurfoundation.org/circular-economy/concept

5. J.-P. Birat, The environment and materials, from the standpoints of ethics, social sciences, law and politics, Matériaux \& Techniques 107, 102 (2019), 10.1051/mat tech $/ 2018067$

7. D.H. Meadows, J. Randers, D.L. Meadows, The limits to growth: The 30-year update, 2004

8. E. Yamasue, Resource paradox problem revealed by total material requirement, in: SAM-13, Pisa, 20-21 May 2019

9. J.-P. Birat, Society and materials: How it all started, a few million years ago, Matériaux \& Techniques 104(6-7), 19 (2016)

10. Recycling rates of metals, Eurométaux, EUROFER, Bruxelles, 2012, Available from https://www.eurometaux.eu/ media/1510/electroniversionrecyclingratesdec2012_eurome tauxeurofer.pdf

11. J.-P. Birat, N. Prum, K. Yonezawa, L. Aboussouan, The value of recycling to society and its internalization into LCA methodology, La Revue de Métallurgie-CIT, 50-61 (2006)

12. J. Gracq, Un beau ténébreux, 1945, $64 \mathrm{p}$

13. V. Hugo, Homme qui rit, 2e tome, 1869, $163 \mathrm{p}$

14. M. Soyeux, À Vannes, une cathédrale palimpseste, Journal La Croix, 11 (2015)

15. J.-P. Birat, H. Lavelaine, The eco-techno-systemic services that steel plays in the energy system, in: SCANMET 2016, Luleå, 2016, keynote lecture

16. J.-P. Birat, M. Chiappini, Recycling and downcycling, in: 7th Conference on Society and Materials (SAM-7), RWTH, Aixla-Chapelle, 23-26 April 2013

17. J-P. Birat, Product innovations of key economic importance for the steel industry, Metall. Res. Technol. 115, 420 (2018)

18. J.-P. Birat, A. Declich, Narratives \& materials, in: SAM-9 Luxembourg, 11-12 May 2015

19. J.-P. Birat, Recycling of tinplate, in: Paris Meeting of the Packaging Working Group of IISI on 5 May 2001

20. J.-P. Birat, L. Rocchia, M. Tuchman, The iron cycle and ecodesign in the automotive industry, in: Green-CARE Conference, 25-28 November 2002, Vienna, Austria

21. J.-P. Birat, MFA as an environment management method in industry, in: SFI Metal Production Spring Meeting, 24-25 April 2019, Trondheim

22. Augustine, Confessiones, $397 \mathrm{p}$

23. Groupe de Montheron, Des hommes de science aux prises avec le temps, Presses polytechniques et universitaires romandes, Lausanne, 1992, $178 \mathrm{p}$

24. M. Foucault, Des espaces autres. Hétérotopies, in: Conférence au Cercle d'études architecturales, 14 mars 1967, in Architecture, Mouvement, Continuité, No. 5, 1984, pp. 46-49.

25. I. Sudradjat, Foucault, the other spaces, and human behaviour, Proc. - Soc. Behav. Sci. 36, 28-34 (2012)

Cite this article as: J.-P. Birat, Palimpsest and heterotopia, metaphors of the Circular Economy, Matériaux \& Techniques 107, $505(2019)$ 